\title{
O CETICISMO NA JUSTIÇA E NO DIREITO EM MONTAIGNE
}

\section{Dalton Franco ${ }^{1}$}

\section{Resumo}

O trabalho apresenta o que pode ser o papel do ceticismo para o direito no pensamento de Michel de Montaigne (1533-1592). Em primeiro lugar, discute a justiça através de uma atitude solipsista. Em seguida, identifica como pode ser configurado o direito a partir do ceticismo pirrônico do ensaísta. Argumenta-se que o ceticismo aparece como diagnóstico e como instrumento de intervenção pela justiça. Ao final do trabalho, apontamos o direito montaigniano como um instrumento de imperfeição contínua, desarticulada de qualquer base dogmática.

Palavras-chave: ceticismo, pirronismo, Montaigne, justiça, direito

\section{INTRODUÇÃO}

Os céticos configuram uma escola singular no período clássico e no período moderno e os seus seguidores, como Michel de Montaigne (1533-1592), trazem desafios críveis sobre a capacidade humana de dizer o mundo e de apontar o justo. Pergunta-se nesse trabalho se um cético pode apontar um direito não dogmático, mais do que isso, discutimos se é possível configurar um meio para a justiça, uma ciência de regras, que trataremos como um tipo singular de direito, sem portanto ter a obrigação de dizer o que é o direito, mas sugerir como ele aparece num cético pirrônico, como é o caso de Michel de Montaigne nos seus Ensaios².

O ensaísta é atravessado por um grande número de referências do período antigo, como ocorria a muitos autores no período moderno, que se iniciara então, mas o que enfatizamos como premissa básica nesse trabalho é o fato de que a fragmentação de referências, a sua dispersão não linear e eventualmente não coordenada, pode ser agregada por um tipo específico de ceticismo, o da escola

\footnotetext{
${ }^{1}$ Doutor em Ciência Política, Teoria Política, pela Universidade Federal Fluminense (PPGCP-2009/2012), Mestre em Ciência Política, Teoria Política, pela mesma instituição (PPGCP-2006/2007) e Graduado em Ciências Econômicas pela Universidade Federal Rural do Rio de Janeiro (ICHS-2002/2005). Coordena o Laboratório John Rawls de Filosofia Pública e Ciência Política - Universidade Estácio de Sá - Rio de janeiro - Brasil. ORCID iD: $\underline{\text { http://orcid.org/0000-0003-3073-9060 }}$ Lattes: $\quad$ http://lattes.cnpq.br/1457561109557662 $\quad$ E-mail: daltonfranco@gmail.com

${ }^{2}$ Neste trabalho as citações dos Ensaios de Michel de Montaigne seguirão a edição brasileira da Editora Martins Fontes, traduzidos por Rosemary Costhek Abílio, ainda que tenhamos consultado outras traduções. Nas referências aos Ensaios, o primeiro e o segundo algarismos romanos apontarão o livro e o capítulo, enquanto o algarismo arábico indicará a página. Conforme exemplo: (I, XXXI, p. 5). Ignoraremos as camadas de alterações feitas ao longo do tempo por Montaigne, normalmente codificadas nas citações pelas letras A, B e C em destaque. Para os propósitos deste estudo, essa classificação seria uma demasia.
} 
pirrônica, aquela que duvida inclusive das próprias proposições. Sua biografia implica na afirmação forte de que era múltiplo: foi magistrado, político, articulador, conselheiro, filósofo, erudito e, talvez a atividade que melhor o defina, foi um pensador não dogmático.

A sua estratégia de uso da linguagem fluida, direta e medida procura estabelecer, segundo parece-nos, uma comunicação contundente contra o dogma, isto sem a necessidade de igualá-lo. Segundo sugere-se aqui, o seu ponto de partida usa como passo estratégico reduzir o papel açodado das novidades e das contrapartes do século e, especialmente, daquela parcela de participação incendiária de uma sociedade em conflito aberto. A saída solipsista aparece-nos como a porta de redução do papel dos dogmatismos e da luta aberta, da guerra civil, de modo que reduzir e recolher-se faria não só um bem a si como ao público. A moderação derivada desse solipsismo emerge então como o justo. A fórmula pode lembrar aristotelismo, mas é montaigniana.

Apontamos essa atitude narrativa como solipsismo cético, como solução mediada rumo à tranquilidade. Na parte final, anotamos uma ciência de regras não dogmáticas, como resposta cética ao mundo social, segundo a qual o direito é autorizado pela crença e não por algum fundamento racional. A base de acreditação do direito em Montaigne é parte de uma sugestão de saber não dogmático, de saber exotérico. O caminho ao justo funda-se na experiência coletiva de crenças decantadas pela prática em instituições.

\section{A DIAFONIA SOBRE O CETICISMO E MONTAIGNE}

Ao procurar um lugar para o ceticismo no direito e na justiça, procuramos um lugar central para a falibilidade humana no seio do inventor e dos positivismos dos processos decisórios dos Estados. O justo como essência, como a meta do direito, implica na regra como meio para a justiça. Em Montaigne essa trindade, o direito, a falibilidade e a justiça, pode ser realizada, muito à moda de sua leitura do juízo como falha de sustentação moral, fora da discussão sobre a separação estrita ou a sua junção unívoca (KIRALY, 2012). Mais importante do que divisar direito, justiça e moral, como Kiraly, aqui procura-se ver como Montaigne percebe uma eventual ciência de regras, sua necessidade sem primazia moral consistente como o positivismo precisa produzir. Por outro lado, em consonância, "a separação entre direito e moral é moral de um jeito vedado à inseparabilidade” (2012, p. 3). Tratamos, portanto, de direito como imagem da autoridade da regra, de um conjunto de crenças apresentadas à autoridade (KIRALY, 2012). A justiça como resultado da crença é o espaço da satisfação apenas pela execução do projeto e não pelo seu termo dogmático. Em linha clara: a aplicação repetida da regra pode terminar na crença da existência da justiça. Não estamos então procurando uma teoria do direito 
propriamente dita, mas antes procuramos apontar como ele pode ser configurado pelo pirronismo de Montaigne.

Ao mesmo tempo, ao interpretar o direito e a justiça à luz do ceticismo precisamos de categorias intrínsecas, ao direito em si, e dele ao mundo. Nessa chave, é preciso superar a querela pura e simples e estabelecer as coisas como elas são no mundo, remover-se do solipsismo cético e abraçar as decisões, pois elas são incontornáveis. Essa leitura também aponta uma direção: do direito ao ceticismo e desse finalmente ao mundo. Isto é possível no ceticismo de Montaigne? À luz da escola suspensiva, parece positivismo travestido de impaciência e a ficção de um tipo específico de ceticismo que atenda ao direito e não ao ceticismo como reunião de obstáculos de justificação, por exemplo (LEITÃO, 2016). Com o aporte de Dworkin, Leitão afirma:

O fato antropológico da diversidade de posições morais está correto, mas esse juízo factual não refuta per si nenhum juízo moral positivo sobre determinada questão. Essa explicação pode interessar na compreensão das causas da convergência ou da divergência em certos temas, mas o momento de decidir sobre a veracidade de juízos morais exige um esforço inevitável de justificação. (LEITÃO, 2016, p. 79, negrito).

Por certo, nosso interesse não é o de proceder do direito ao ceticismo e a uma de suas versões, mas o oposto, percorrer o ceticismo e extrair dele e de Montaigne qual fabulação pode ser conferida à autoridade das regras. Na passagem evidencia-se um caminho diverso. Não trabalhamos com ele pela razão que segue. O ceticismo mais geral, especialmente a versão mais caótica, a mais cáustica, a pirrônica, como a de Michel de Montaigne, não se ocupa de asseverar o que seja e sequer da variedade de oposições, menos ainda de colocar-se no "momento de decidir", de concordar com a inevitabilidade, com a necessidade e menos ainda de esposar uma justificação. A razão é simples: o pirronismo suspeita inclusive das próprias dúvidas. Os fundamentos e as crenças não são imagens dissociáveis ao pirronismo, pois a crença pura e simples em qualquer fundamento cria o assentimento, e este é o fundamento puro e simples para a ação. Um fundamento qualquer, para um cético profissional, não possui base que por sua vez não possua, por exemplo, ao menos uma imagem antagônica. Portanto um pretenso fundamento não traz autoevidência mais potente que ou menos potente que, de modo que um pirrônico apenas assente preferencialmente à ataraxia, a moderação, ao fenômeno como aparência, e não como essência fenomênica. Da mesma forma, assentimento e juízo não são a mesma coisa, salvo muita desenvoltura na potência da solução racional.

Um relacionamento literal entre o direito e os Ensaios de Montaigne propriamente dito é obra de Gilmar Conceição (2015), isto do ponto de vista do fenômeno e de sua recorrência, e um pouco 
menos do que uma teoria do direito propriamente dita ${ }^{3}$. Portanto, desce da projeção da imagem interna que supera o obstáculo cético com uma leitura da lei como aparece a Montaigne e ao seu ceticismo pirrônico. O trabalho apanha dois Ensaios capitais para os temas da justiça e da lei, "Da experiência" (I, XXIII) e “Do costume...” (III, XIII), e deles aponta o tratamento dado pelo ensaísta, a partir de sua formação jurídica, como magistrado, do seu exercício funcional e de sua experiência como político, ainda que demarque bem as distâncias entre o que chamamos hoje de magistrado e as funções ambíguas envolvidas nesse conceito no século XVI. Para o autor, portanto, o fato de Montaigne ter sido formado magistrado e de ter operado como uma figura pública o apresentaram a um horizonte de críticas à fabricação de leis e do que chamavam de justiça.

O trabalho aponta para o que seria o direito, a justiça e a lei a partir dessa perspectiva experimental vocalizada nos ensaios do eu. Para o Montaigne de Conceição (2015), o prestígio da lei vem do fato de ser praticada, não do fato de ter um fundamento específico do ponto de vista doutrinário ou filosófico, a autoridade da lei vem do fato de ser lei, sua autoria é vã e incerta (2015, p. 901). Não há horizonte linear porque "usam-se critérios diferentes para as mesmas coisas, ao se tratar com aliados ou com adversários" (CONCEIÇÃO, 2015, p. 901). Os dois ensaios são de fato capitais para entender o ensaísta e a sua relação com as instituições de justiça. Por outro lado, dada a escassez de trabalhos contíguos, procura-se aqui ocupar outro espaço e com outros Ensaios que não esses e evitar-se ainda a repetição de caminhos em Montaigne. Isso não figura um elogio preliminar ao artigo ou um escapismo destes ensaios, mas por ora a jovem e virtual sociedade brasileira dos amigos de Montaigne ${ }^{4}$ parece exigir uma rota alternativa para um alvo contíguo.

Danilo Marcondes, em "Montaigne, a descoberta do Novo Mundo e o ceticismo Moderno" (2012), abre uma leitura distinta sobre os estudos de frente para a ênfase antropológica oferecida sobre os Ensaios, e em especial para o famoso "Dos Canibais" (I, XXXI). A ênfase do argumento recai então sobre a natureza humana do canibal brasileiro e a natureza pretensamente inumana do europeu, sobre o choque de culturas acostado nos modos da relatividade de Sexto Empírico. O artigo traz o eterno discurso sobre as imprecisões de Montaigne e o ineditismo na reflexão sobre o verdadeiro canibal, se o europeu ou se o ameríndio, e que, imagina, revela uma solução de purgação dos preconceitos e o olhar aberto para a diversidade de culturas humanas, em lugar de uma generalidade e de uma essência universal. Baseado então sobremaneira naquele ensaio, propõe olhar para Montaigne como sendo o

\footnotetext{
${ }^{3}$ Para outra abordagem sobre o direito, o ceticismo e a linguagem, ver o artigo Direito e linguagem no pensamento de Montaigne (GOMES; PALIOLOGO, 2018).

4 Baseado em La Société des Amis de Montaigne (http://www.amisdemontaigne.fr/), apenas indicamos metaforicamente a parcela crescente de leitores e pesquisadores de Montaigne no Brasil.
} 
primeiro autor de fato moderno, cuja inauguração do período reflete a questão sobre o que é a civilização em si.

O trabalho de Marcondes (2012) com "Dos Canibais" é articulado com uma feição antropocêntrica, como a indagar o que é o homem e o ambiente, o diverso e a sua explicação. Nesse ponto em especial, marca o ceticismo como método de resolução, como rota segura de paradigma interpretativo, pois ele pode ligar o diverso, a pluralidade de influências clássicas do ensaísta, a sua escrita pretensamente não esquemática e trivialmente não dogmática, para evitar depender de chaves contemporâneas como a empatia, a alteridade e o imperialismo. O emprego do pirronismo como ligação de pontos dos Ensaios é prudente e adequado, por outro lado, o uso repetido do canibal com ênfase no homem e no ambiente parece não contornar a autonomia do político e da eventual leitura contratualista bastante antecipada. Portanto, crê-se aqui que há uma agenda de estado de natureza e de civilização a ser feita. Por enquanto, esse trabalho, a despeito da concordância metodológica com Marcondes, projeta o que pode ser uma ciência de regras que chamaremos de direito e como ela pode ser fabulada por Montaigne.

Maria Theobaldo, em "História e exercício do julgamento em Montaigne" (2012), traz a vista para os aspectos dialógicos do texto de Montaigne. Deixa clara a intensão do ensaísta de conversar para convencer, para orientar a conduta do mundo em fragmentação. De acordo com a autora, o ensaísta está a abrir o "livro do mundo" com a sua fala em formato livre, pois escreve como quem conversa com a história, com o leitor, cujo sentido é orientado do mundo para si, do ambiente para o eu. Segundo o artigo, a história é tomada nos Ensaios de modos distintos, mas nunca como exemplo, como realidade, como previsão ou como base segura para os juízos, antes o contrário e, mais especificamente, é vista por ela como uma fixação da reflexão aberta e simpática às contingências humanas e também como uma reflexão sobre o diverso e a sua constância manifesta na imprevisibilidade. Segundo a autora: "Montaigne procura mostrar que os exemplos buscados na história, nas sentenças morais ou na tradição não oferecem uma saída segura para o conhecimento sobre os homens e para a previsão de suas ações [...].” (2012, p. 536). A falha do juízo humano no tempo é um alento de moderação que pode ser difundido na contingência de Montaigne. A abordagem do juízo na história colabora para o aterrissarmos no tempo e na técnica do direito, na operação da suspensão do juízo sobre o verdadeiro e o falso e, assim, colocar no mundo um pouco mais de tranquilidade em lugar de tensões dogmáticas.

A multiplicidade de abordagens dos Ensaios, a diafonia dos amigos brasileiros de Montaigne, não é apenas importante, e todas as leituras são também necessárias. Sem a presunção de realizar um trabalho exegético sobre os fundamentos do direito em Montaigne, ao largo disso, aponta-se para a 
possibilidade de adequação entre o ceticismo e o que chamamos de sistema de justiça humana. A falibilidade tem lugar destacado no pretenso direito de Montaigne, ela tem também lugar lúcido nas ciências de regras em geral atacadas por ele. A interpretação que apresentamos sobre os Ensaios dirigese do ceticismo pirrônico ao direito e dele ao mundo. $O$ trabalho inverso, o de apresentar exaustivamente como é o direito pela via dogmática, ainda é um exercício a ser feito. Portanto, no estreito limite da filosofia política, que papel tem o direito no pirronismo de Montaigne? O direito pode oferecer perguntas mais nítidas do ponto de vista das ciências de regras, de modo distinto, apresentamos aqui uma abordagem do caos montaigniano para a ordem social agregada. Não está em discussão apresentar uma interpretação sem incorrer em dogmatismo, mesmo que seja atrás da escora do ceticismo como aporte metodológico, pelo contrário, procura-se apenas apresentar o pirronismo como item incontornável quando lemos os Ensaios. E se ele é indispensável, incorremos na precipitação de dizer o que o ensaísta não dispensa. Seja como for, para o que propomos, extrair um dogma de um pirrônico, parece menos oneroso e mais aglutinador do que o caminho da leitura dos Ensaios como mero relato do real através de fragmentos do eu.

\section{O JUSTO PELA BULA SOLIPSISTA}

Devem-se a Michel de Montaigne (1533-1592) um punhado de profissionalismo cético. Mais do que uma escola de suspensão do juízo, essa atitude intelectual praticada pelo ensaísta coloca em questão toda a projeção descritiva, prospectiva e dogmática sobre como o julgamos o mundo. $\mathrm{O}$ caminho habitual do ceticismo é composto de passos bem marcados e que são emulados ao longo dos Ensaios de Michel de Montaigne (Ensaios). O trajeto começa pelo método de oposições, em seguida atravessa a equiparação de asserções dogmáticas, no qual o argumento $A$ tem tanta substância quanto o argumento $B$, e do que então decorre uma experiência leve, decorre a suspensão do juízo sobre o mundo, sobre a essência de $\mathrm{A}$ ou $\mathrm{B}$, que por sua vez é aditada de uma fina passada final rumo à tranquilidade da alma (SMITH, 2012). Em termos sumários: diante da querela dogmática, a suspensão do juízo retorna como prêmio uma vida tranquila. Naquela França conflagrada do Século XVI entre papistas e protestantes, entre reformadores e contra reformadores, para Montaigne, entre duas facções dotadas de argumentos igualmente válidos, a justiça é inaparente, ela não se revela, de modo que o justo, o que chamamos de ordenamento justo, seria epistemologimente inapreensível (POPKIN, 2000).

Naquele instante, naquela quadra de século, e sem a exclusividade daquele século, a razão pública era assolada por idiossincrasias, por razões privadas lanças ao mundo, adornadas em sedução estética, por meio da força e cujo resultado nédio era a dissolução prática da própria autoridade do 
Estado, ponto pacífico em Montaigne como na historiografia das ideias (SKINNER, 1996). O ordenamento social ${ }^{5}$, o agregado, habitualmente conhecido por um acordo público de instituições sensíveis, de legislações, de costumes e de crenças, era posto em discussão e era solapado por soluções racionais privadas, através de crenças idiossincráticas, como a razão protestante, a razão desafiante, a inovadora, contra a razão pública estabelecida, cujo resultado redundava em fragmentação, em dissolução e em dissipação do Estado e, em última observação, no esfacelamento de um estado de coisas. Para Montaigne, ao mesmo tempo, parece-nos, o ceticismo é um diagnóstico, um corolário do conflito de filosofias e um instrumento ativo, diante do que podemos chamar de torneio de razões, de fuga e de promoção solipsista. Trata-se de tocar o mundo e a injustiça com ceticismo e de projetar o mundo e a justiça com outro ceticismo. A partir do pirronismo de Montaigne, a justiça não pode ser posta no mundo pela razão privada dos homens, nessa posição ela só pode ser representada violentamente pelas paixões humanas, tal como o conflito lhe aparece. No ceticismo como diagnóstico da chamada diafonia, cujos termos circunscrevem um desacordo humano inerradicável, a razão idiossincrática, a desafiante, é uma válvula de injustiças aberta por si e que, por outro lado, como réplica, sofre a reprimenda odiosa, a admoestação pela representação coletiva da razão pública, de sorte que o inovador sofre a repreensão raivosa das tradições. Em linhas claras, no ceticismo de Montaigne, a querela dogmática ataca a tranquilidade do Estado "com esses aborrecimentos do mundo" (I, XXXIX, p. 354).

A partir disso, do ponto de vista contemporâneo, permanece aberta entre montaignistas, leitores e entre os maus leitores do ensaísta a questão sobre a sua possível animosidade ao desafiante e a sua possível simpatia ao quadro legal e a ordem social constituída. Ainda que seja uma discussão do nosso tempo, a pergunta não é menos importante, ela ainda nos toca porque perturba um item caro no passado como agora, a inovação importuna a tranquilidade. Frame, um reconhecido montaignista, coloca esse tópico com clareza e com a devida complexidade: how important to his religious position is his political conservatism? (1963, p. 584). Pensá-lo conservador é não só possível quanto desejável, desde que não se ignore pensá-lo como um inovador, por exemplo, como o antecipador de questões e de ainda prestigiados princípios liberais, campo no qual the concedem muita sombra e muito esquecimento em lugar de emprestar-lhe a luz da discussão intelectual do Estado moderno. Quando se anota o contratualismo e o neocontratualismo costumeiros, com poucos nomes, deixamos claro também o tamanho da nossa avareza com o trabalho do ensaísta. Seja como for, está fora de propósito desse texto desenvolver a discussão sobre o papel de Montaigne no contratualismo, no liberalismo e

\footnotetext{
${ }^{5}$ O rawlsianismo chamaria isso de "estrutura básica da sociedade". A este respeito basta observar "Uma teoria da justiça".
} 
no pensamento conservador, está por certo no horizonte apenas apontar a justiça pública à luz de um ceticismo profissional.

Com brevidade, o ceticismo como diagnóstico pode ser suficiente para uma leitura de dentro para fora, para uma leitura de contexto ao texto dos Ensaios, por outro lado, em sentido diverso, do texto ao contexto, do ceticismo como instrumento, dois Ensaios podem sinalizar o espraiamento do pirronismo grego, apontar a sua natureza, e como Montaigne o emprega na leitura das disputas irresolutas do seu mundo e do mundo. No Livro I dos Ensaios, onde para o montaignista Donald Frame o ensaísta "[...] is more the man [...]" (1963, p. 581), em "Como choramos e rimos por uma mesma coisa" (I, XXXVIII), temos a presença de Sexto Empírico, um dos maiores organizadores do ceticismo grego, lido com atenção por Montaigne (EVA, 2012), quando lemos que “[...] ao julgar esses acontecimentos é preciso considerar como nossas almas amiúde se acham agitadas por sentimentos diversos [...]" (p. 349), o que nos sugere, por exemplo, o argumento das condições ideias do corpo para o juízo perfeito, os modos da natureza do sujeito (SEXTO EMPÍRICO, 2000). Em síntese, não temos o adequado quadro de condições internas para o melhor julgamento externo e a promoção da justa sentença, “[...] nenhuma qualidade nos abarca pura e totalmente [...]” (p. 351), de sorte que há crianças que choram e que sorriem duma mesma coisa (p. 350) e que há adultos incompreensíveis que lamentam por indivíduo morto “[...] que não queríamos que estivesse vivo [...]” (p. 350). Extrai-se que: nosso juízo é diverso e desconexo em qualquer trecho da vida.

O ensaio "Como choramos..." (I, XXXVIII) prepara o terreno, assim nos aparece, para um quadro projetivo e para a proposta normalizadora contra o avanço das idiossincrasias ruidosas do tempo. Para os leitores treinados de Montaigne, com relativa frequência, o ensaio anterior pode não ter qualquer relação com o posterior, de sorte que a conexão linear entre ambos, para os propósitos desse artigo, fixa um pequeno breviário de método de interpretação, fixam apenas como os lemos aqui. Dessa laboriosidade surge a avareza de leitores do ensaísta. Em que pese essa dificuldade analítica, desta feita, em seguida, no ensaio "Da solidão" (I, XXXIX), o intelectual e magistrado fala de como isolarse para conhecer-se, para afastar-se da produção de uma razão não pública de característica fragmentadora. Diante do sintoma dogmático, diante da certeza pessoal indubitável, segundo Montaigne, a fragmentação pessoal implicaria numa imobilidade restauradora, para não desafiarmos os laços públicos com razões privadas, isto se atingimos a “[...] solidão verdadeira [...]” (p. 358). A noção sensível e inteligível de falibilidade pública pode ser arrefecida com a clara noção cética de falibilidade privada e que, como conclusão, ao arrepio das perfeições, das infalibilidades, espera-se a tranquilidade pública. Em outros termos, a noção de fraqueza na autocondução do sujeito pode apresentar o enfermo (o dogmático) a um quadro de criterização mais radical sobre a concepção privada e sobre a concepção pública de justiça. Em "Da solidão" (I, XXXIX), a perfeita justiça 
dogmática espelha a mais perfeita desagregação política, a justiça pública imperfeita espelha a menos imperfeita agregação política. O otimismo idiossincrático do inovador e o do contra inovador, dois dogmáticos, são fragmentadores da ordem agregada, o pessimismo ontológico e a antropologia montaigniana, segundo lemos, então seriam projeções sensuais pacificadoras, tranquilizadoras. Os itens de comércio são: a justiça particular pela justiça pública (coletiva); a perfeita injustiça dogmática (idiótica) pela imperfeita justiça cética pública.

Tratamos então este sussurro público salvacionista de ceticismo como instrumento que, diante da fissura idiótica mobilizada pelos dogmáticos, serve de válvula de agregação e de sedimentação política. Os racionais dogmáticos matam-se pela verdade, por sua vez, o ceticismo montaigniano os convida novamente à vida, à tranquilidade pública. Uma das grandes questões para Montaigne, como para os tempos vigentes, é como fazer a razão reconhecer o seu lugar na turbulência e na tranquilidade. Pode-se responder parcialmente nesse texto, pode-se apenas sondar o insondável pela razão, como ele diria e como fez, pode-se beber água como os cães da fábula de Esopo para aproximar-se de um objeto reconhecível no oceano. Por meio de ensaio público, de sedução e de retórica literária, através da pesquisa pública de si projetada nos Ensaios, através da fixação escrita do pensamento, através da imortalização da falibilidade humana (I, XXXIX, p. 364-65). Trata-se assim de terapia pirrônica, de procurar afogá-la em ceticismo frio, metódico e de recuar a justiça racional dogmática até o seu pequeno alcance privado, claudicante e curto.

Dito de outro modo, a instrumentalização do ceticismo introduz um solipsismo radical e incompleto, impõe um verdadeiro cerco epistêmico contra a razão, porque de certo "[...] é preciso isolá-la em si mesma: essa é a solidão verdadeira e que pode ser desfrutada no meio das cidades e das cortes dos reis; mas é desfrutada mais comodamente no isolamento.” (I, XXXIX, p. 358). Torná-la “[...] tão privada que ninguém de nossas relações e nenhuma comunicação de fora encontre espaço [...]" (p. 359), evitar o seu comércio se não tiver produto adequado, assim, preconiza: "[...] quem não pode emprestar, evite tomar emprestado [...]”. (I, XXXIX, p. 361).

A introspecção montaigniana sugere ainda que "adule-se e se afague, e acima de tudo se governe, respeitando e temendo sua razão e sua consciência, de tal forma que não possa sem pejo tropeçar na presença de ambas" (I, XXXIX, p. 361). Uma nova legião de dogmáticos atomizados não funda uma ciência de regras, uma ciência pública, e dessa maneira "há ciências estéreis e espinhosas, e na maioria forjadas para as multidões: é preciso deixá-las para os que estão a serviço do mundo" (p. 367). Aliar-se a uma teologia e confundi-la com uma teleologia soberana é não só temerário quanto perigoso, nesse caso, as ciências privadas devem permanecer em privado, as ciências públicas ocorrem 
entre os que estão a serviço coletivo e não servindo-se do mundo (p. 354). De qualquer modo, um enfermo dogmático não cura com facilidade, portanto, Montaigne redobra o tratamento:

Eles simplesmente recuaram para saltar melhor, e para, com um impulso mais forte, penetrar mais fundo na multidão. Gostaríeis de ver como erram o salto por um pouquinho? Coloquemos de contrapeso a opinião de dois filósofos, e de duas facções muito diferentes, escrevendo um a Idomeneu, o outro a Lucílio, amigos seus, para, do manejo dos negócios e das grandezas, retirá-los para a solidão. (Ensaios, I, XXXIX, p. 368).

O que a passagem sugere, segundo nos aparece, é a insuspeita diafonia, o desacordo inerradicável entre as muitas concepções de mundo para refrear a ambição da novidade. E como resultado, o ataque perdura: “[...] que o público vos seja um, e um vos seja todo o público [...]” (p. 369), pois é "[...] uma covarde ambição pretender obter glória da ociosidade e do isolamento [...]” (p. 369), é impossível ignorar que “[...] há meios de falhar na solidão, como em companhia” (p. 369), devemos desistir “de uma filosofia ostentatória e verbosa [...]” (p. 369). Deve-se, outrossim, “[...] fugir em geral das paixões que impedem a tranquilidade do corpo e da alma [...]” (p. 366), “[...] desvencilhemo-nos dessas dominações violentas que nos comprometem alhures e nos afastam de nós [...]” (p. 361), chegou o tempo de “[...] nos desprendermos da sociedade, já nada lhe podemos oferecer [...]” (p. 361), finalmente, “[...] devemos reservar-nos um cantinho retirado totalmente nosso, totalmente independente, no qual estabeleçamos nossa verdadeira liberdade e nosso importante retiro e solidão [...]" (p. 359).

O que se sugere aqui é uma doutrina solipsista de Montaigne como um instrumento de arrefecimento da diafonia representada pela letalidade dos conflitos. Um sujeito cético que pratica solipsismo é um moderado em matéria de consórcio público, uma novidade contra o esfacelamento, uma restauração cética diante da desagregação. $\mathrm{O}$ atingimento do justo é trabalho de solipsistas ou o solipsismo cético fixa a agregação pública. O que esse indivíduo e sujeito sensível relata ao mundo é uma justiça repousada sobre a vida tranquila, diante da vida das agitações performáticas dos dogmáticos. Nesse aspecto, a estrutura discursiva do sujeito cético é capaz de trazer a justiça para o seu lugar fora da arrogância das razões idiossincráticas. A tranquilidade cética é uma meta de justiça pública desprendida de totalizações coerentes, o ensaio do primado das imperfeições públicas sugere o primado das imperfeições privadas, além disso, o primado da razão pública sufoca o primado da solução dogmática. A interação das decisões institucionais entre os sujeitos no decorrer do tempo dá, em Montaigne, precedência sobre as inovações do sujeito sem interações de reconhecimento público ${ }^{6}$.

\footnotetext{
${ }^{6}$ Isso não é exatamente o mesmo, por exemplo, de uma categoria funcional da razão apresentada por Mbembe no ensaio Necropolítica: "a razão é a esfera do sujeito, e o político é o exercício da razão na esfera pública.” (2016, p. 124).
} 
A falta de radicalidade privada é um tormento para uma radicalidade pública reconhecida com os anos, com as tradições e com as experimentações coletivas. No ceticismo montaigniano, sem pré-requisitos de coerências particulares, a justiça é atingida quando encontramos a tranquilidade privada em consonância com a vida pública. O ensaio cético e radical das faculdades do sujeito, um solilóquio suspensivo profissional, é meio de sondagem da justiça pública.

A justiça dos homens é um bem sondado apenas como coisa que aparece, não como essência revelada. A avaliação demasiado otimista de inovadores e de contra-inovadores requisita, em Montaigne, moderação e recolhimento, em lugar de retórica de vias de fato, de litigação com justiçamento. O livro sugere o recolhimento, a observância das falhas, das mudanças e da falta de fundamentos especiais nos próprios devaneios. A organização pública requisita, aos olhos do ensaísta, bastante comedimento da razão em defesa da vida. A defesa da vida é um direito, a defesa da morte é um delírio idiótico a ser evitado pela moderação cética. $O$ solipsismo radical pode lembrar a falibilidade restauradora (FRIEDRICH, 2001), pode apontar pelo magistrado a resposta ao conflito aberto. Uma de suas principais perguntas é um belo fio condutor de solipsismos: Que sei eu? Em seguida, verificaremos as implicações da pesquisa de si.

\section{O DIREITO COMO SINTOMA DA INJUSTIÇA: AS COISAS POR VIR}

A questão que subjaz do homem de razão, rebaixado em solipsismo cético, é como produzir uma ciência de regras que anime e que operacionalize a direção do justo. Se o conhecimento dos limites da razão idiótica aplacaria a virulência pública e o colapso das instituições (I, LIV, p. 466), por outro lado, e em adição, uma ciência de regras de acolhimento de conflitos é extraída ontologicamente da mesma matriz. Este é o caso ainda do Ensaio "De uma sentença de César” (I, LIII), de onde fica claro que, da imperfeição, de "[...] peças frágeis e falhas [...]” (I, LIII, p. 460) nasce o imperfeito, a insatisfação com o resultado público junto ao assentimento público são a via de acesso e o resultado do que chamamos de direito, a partir dos Ensaios, posto que "[...] não conseguimos assentar nosso contentamento em coisa alguma [...]” (LIII, p. 460). Para a sua animação, exige-se a correlação necessária entre a insatisfação e o assentimento, exige-se assentir em desacordo. A irresolução, a pacificação e a descompressão de conflitos por uma ciência de regras públicas é gerada por um esquema tão precário quanto necessário de conservação da vida, isto porque “[...] nosso apetite é indeciso e incerto: não sabe conservar coisa alguma, nem desfrutar nada da maneira certa [...]” (I, LIII, p. 461). Os sistemas e os seus operadores são sintomaticamente reflexos de processos de aprendizados e de ignorâncias que serão eventualmente resolvidos no decorrer do tempo da experiência humana, o conhecimento engendra a ignorância e o desejo de superá-la, a ignorância é dominante como um argumento regressivo típico do pirronismo (I, LIV, p. 465). A esse respeito, ainda que o autor não 
invista numa teoria das regras, vejamos como ele descreve a matriz do que poderemos chamar aqui de Direito:

Não importa o que venhamos a conhecer e desfrutar, sentimos que não nos satisfaz, e perseguimos cobiçosos as coisas por vir e desconhecidas, pois as presentes não nos saciam; em minha opinião, não que elas não tenham o bastante com que nos saciar, mas é que nos apoderamos delas com mão doentia e desregrada [...]. (Ensaios, I, LIII, p. 461, negrito).

Desta base frívola, podemos dizer que a ciência de regras humanas explícitas expressa de fato uma reapresentação dos precários repetidos e não necessariamente replicado no decorrer do tempo. Nosso apetite pelo desregramento é superior à toda a capacidade ordinária de por e de ser fiel a um código moral universalizante, respeitável e exequível, seja por princípios dogmáticos ou racionais. $\mathrm{O}$ dogmatismo e o racionalismo não seriam, em Montaigne, portanto, sinônimos, mas sim apartados e eventualmente combinados. O desregramento pode ser experimentado por um dogmático, através de uma simples convicção de senso comum e, de maneira análoga, através de um dogmático racional, por um pensamento jurídico em sentido escolar. Os rábulas e os juristas, por exemplo, não são mutuamente excludentes, se imaginarmos o primeiro como o operador do senso comum e o segundo como o acadêmico, para desenhar em linhas claras essas duas categorias didáticas de sintomas de idiossincrasias (I, LIV, p. 465). O que Montaigne nos sugere com a passagem do Ensaio "De uma sentença de César" é que uma regra moral dirigente composta de códigos de prêmios, de soluções e de sansões do ponto de vista dos dogmáticos será um eterno por vir, uma solução normalmente distante da experiência sensível, alheia à simpatia vigente com a justiça.

O que está em discussão seria então um percurso e um destino pela imperfeição e pela falibilidade: um delírio de precipitação sobre meios e um delírio de precipitação sobre fins. Em outras palavras, o direito é um tipo de mecanismo vacilante para as ambições da justiça, uma sutileza frívola e vã “[...] por meio das quais os homens às vezes buscam prestígio [...]” (I, LIV, p. 463), mas retalhado de modo incontornável por todas as imperfeições e precariedades de ambos. Essa afirmação não traz ainda muita novidade ao direito como o percebemos. O que o distinguiria e o que poderia singularizar Montaigne talvez seja um diagnóstico tóxico sobre e leitura do direito como uma espécie de justo precipitado (apressado) por um dogmático e a leitura da justiça como o direito erguido nas mesmas bases doentias, a doença do dogmatismo, "[...] doença irritante, a de se acreditar tão forte a ponto de convencer-se de que não é possível acreditar no contrário!” (I, LVI, p. 477). O sintoma é a precipitação, a decantação, a crença inabalável do dogmático de ter inequivocamente encontrado a essência das regras. 
Dada a nossa vista desregrada, em Montaigne, o direito nunca poderia ser lido como uma operação possivel, pois configuraria para ele um dogmatismo probabilístico ou um ceticismo probabilístico, da Academia e de Cícero, mas sim poderia ser animado como item do quadro médico dogmático, como por vir, como desfile contínuo de por vir no decorrer do tempo humano, como imperfeição clara e recorrente na experiência humana. No Ensaio "Das Orações", tomamos conhecimento que somos inquietos, disformes e desarmônicos, afinal, "qual prodigiosa consciência pode conseguir descanso criando na mesma morada, numa convivência tão harmoniosa e tão pacífica, o crime e o juiz?” (I, LVI, p. 476). Para ele, a ignorância e a ciência atabalhoam-se no tempo, pois “[...] há uma ignorância abecedária, que antecede a ciência [...]” (I, LIV, p. 465), que poderíamos traduzir e representar como o momento dominante do rábula ou do prático, “[...] e [há] uma outra [ignorância], doutoral, que surge depois da ciência: ignorância que a ciência faz e engendra, assim como desfaz e destrói a primeira [...]” (I, LIV, p. 465) [acréscimos adicionados], que poderíamos traduzir e reapresentar como o momento da ignorância jurídica escolar.

Por seu turno, o justo dogmático está bem compreendido pela mesma passagem, pelo desfile de precipitações, por outro lado, o justo montaigniano se distingue pelo caminho do ceticismo, pela vida tranquila, pela ataraxia, pela apreciação do fenômeno da justiça sem a precipitação autorreferida. A tranquilidade se confunde com a justiça, isso por exaustão das asserções do justo dogmático. Como produto humano, a operação ao justo é uma expressão a mais das imperfeições privadas, meramente funcional para a agregação pública, de sorte que não há alento e fundamento nas leis, não há caminhos fundados para o direito, há apenas as leis como aparência e os seus resultados multidirecionais, de modo que atrás das leis não está o direito e no horizonte do direito não está o justo. Não há linearidade, concomitância e complementariedade em lei, direito e justiça, tocam-se de modo insondável e desregrado, por acidente, como no Ensaio "Das Orações”: “[...] chamamos Deus e seu auxílio para compactuar com nossas faltas, e o convidamos à injustiça.” (I, LVI, p. 483). Em Montaigne, poderíamos dizer algumas asserções não dogmáticas como as que seguem: o direito aparece-nos, qualquer asserção além dessa é fantasia; a lei aparece-nos, qualquer asserção além dessa rima da mesma forma; a justiça aparece-nos, de modo que especular sobre a sua essência não lhe faz justiça, apenas redundamos em injustiça.

A ciência de Montaigne só pode ser configurada fora do ambiente dogmático, o que o coloca ou como um inovador, aos olhos das ciências dogmáticas do presente, pois não são pequenos os grupos dos que desejam as ciências de regras não dogmáticas, ou como um cético inoportuno, pois não oferece sossego teórico para as investidas de representações coerentistas de todas as ciências. O Ensaio "Dos canibais" (I, XXXI), bastante usado pela marcação antropológica, pela empatia ao modo do relativismo sextiano, pela qual abre-se o elogio singular do homem primitivo, é austero e cáustico com o otimismo 
do que chamamos de processo civilizatório, tratando-se de puro elogio ao que chamamos de período pré-estatal e de estado de natureza e, de onde também aparece a caracterização do Montaigne magistrado, em passagem famosa ele anota em conversa hipotética com um filósofo:

É um povo [a população indígena brasileira], diria eu a Platão, no qual não há a menor espécie de comércio; nenhum conhecimento das letras; nenhuma ciência dos números; nenhum título de magistrado nem de autoridade política; nenhum uso de servidão, de riqueza ou de pobreza; nem contratos; nem sucessões; nem partilhas; nem ocupações, exceto as ociosas [...]. (I, XXI, p. 308, negrito e acréscimo).

O entusiasmo com os canibais brasileiros, “[...] no lugar onde Villegagnon desembarcou [...]" (I, XXI, p. 303), traz uma série de elementos do ensaísta, como uma boa quantidade de imagens do direito como a de sucessões, para citar apenas uma, mas fixemos certa estupefação com uma vida onde granjeia a injustiça e outra onde vige a suposta justiça. A lei natural e a lei artificial colidem em significados e na produção do direito e do justo, a primeira, “[...] pouco abastardada pelas nossas [...]" (I, XXI, p. 308) fez justiça alhures, a segunda fez injustiças na Europa, e deste comércio ele prognostica: “[...] desse contato nascerá a ruína deles [...]” (I, XXI, p. 319). A vida de ignorância préestatal afigura-o o horizonte do justo, do inalcançável, da vida tranquila como deve ser. Isto abre espaço para denunciar-se um dever ser em Montaigne, um saber nomotético, mesmo dentro do ceticismo mais caótico como o do pirronismo, abre-se a visada de um quadro normatizador da vida. A ignorância dos canibais os faz abrir o comércio com os estrangeiros e ela mesma, e não a ciência, acossa a tranquilidade cética na qual viviam: “[...] ignorando o quanto custará um dia à sua tranquilidade e à sua felicidade o conhecimento das corrupções de cá [...]” (I, XXI, p. 319, grifo nosso). Com este ensaio, ainda que famoso, permanece aberta uma agenda de pesquisa em Teoria do Estado, Teoria Política e em Contrato Social, ainda por ser produzida com o tamanho que a obra merece, dado que o aspecto relativista já há muito tempo é trabalhado pela antropologia, como no bom selvagem de J. J Rousseau.

De qualquer forma, a despeito do trabalho de decifração do intrincado programa nomotético em Montaigne, as ciências de regras são inevitáveis, conforme o Ensaio "Da moderação":

As ciências que regulamentam os costumes dos homens, como a teologia e a filosofia imiscuem-se em tudo. Não há ação tão privada e secreta que escape ao seu conhecimento e jurisdição. Muito ingênuo são os que lhes criticam a liberdade. (Ensaios, I, XXX, p. 296, negrito).

A despeito da diafonia, da incontornável querela e do desacordo sobre a natureza das coisas, o direito funcionaria como a ligação pública, como a imperfeita ligação coletiva e de aceite tácito, de aceite compartilhado, de maneira que estamos tratando de rejeição cética da razão idiótica e de um assentimento cético com o que podemos chamar de razão coletiva. Ainda que incomode, como em " $\mathrm{Da}$ 
moderação", pois a grande fábrica de técnicas de regras imiscui-se "em tudo", conforme a última passagem, é um tormento de agregação e sujeição coletiva. A frase final da passagem, ambígua e misteriosa como tantas nos Ensaios, aparece-nos aqui como um toque de realismo normativo, senão deslize nomotético, se podemos dizer isso, com relação às ciências de regras, isto porque ela também pode referir-se à mulher e à sua liberdade, conforme continua o texto, mas seja como for tomamos por oportuno a primeira interpretação. O que queremos sugerir é que a ingenuidade não é uma via possível, que criticar a imissão da norma por si não sinaliza nenhuma aglutinação de um século em franca atomização social, pelo contrário, sinaliza a dissipação social. Mesmo que saiamos do contexto, em comparação com "Dos canibais", por exemplo, a tranquilidade coletiva é mais relevante do que a perfeição dogmática deseja fazer crer com soluções precipitáveis.

Se por um lado o contratualismo deve ao bom selvagem, uma imagem bastante famosa, extraída ao que tudo indica do Ensaio "Dos Canibais" (I,XXXI), de Montaigne, e se este ensaio de fato coroa e populariza a antecipação do ensaísta em matéria de nascimento e cotejo da sociedade civil, como insistimos em chamar, por outro lado devemos um pouco mais de atenção ao Ensaio "Da Amizade" (I, XXVIII). É dele de onde surge um grande número de traços “[...] grutescos e [de] corpos monstruosos, remendados com membros diversos [...] (I, XXVIII, p. 274) [acréscimo] do apetite dilatado pela ciência de regras de conduta humana rumo à tranquilidade cética. As regras não trazem essencialmente o bem, o direito, a sua discussão é que configura uma perturbação monstruosa, que precipita sobre o mundo a guerra civil, o esfacelamento. Entre o bom e o mau selvagem, Montaigne parece sugerir a tranquilidade pirrônica, entre dois alvos inatingíveis, ele prefere a escola que ama a vida, a amizade e a quietude. Assentir às regras vigentes, como efeito imediato da suspensão do juízo, significa apenas apontar que a fantasia dogmática não operou com a devida cautela pública, agiu com imperícia por amor próprio, isto porque, afirma Montaigne, não existe “[...] algo que a natureza pareça nos ter encaminhado tanto como para a sociedade. E diz Aristóteles que os bons legisladores ocuparam-se mais da amizade que da justiça [...]” (I, XXVIII, p. 275). Ao abraçar o passado longínquo, abraça ainda o curso de regras, não o por vir dogmático, portanto, há dois salvacionistas em disputa: o dogmático e o cético. O exemplo pirrônico é o da antiguidade, o lastro que pode arrefecer a animosidade à regra em vigor, não porque seja um bem em si, mas por ser um fenômeno aparente, tradicional, por sempre termos sido guiados por condições gerais de conduta, de sentimento público, de amor coletivo, por sua vez, o salvacionista dogmático, aquele que sugere a inovação nas regras, o que projeta um novo marco de regras, para Montaigne, é um delirante açodado, idiossincráticos “[...] que procuram perturbar e mudar o estado de nosso governo [...]” (I, XXVIII, p. 290), prefiguram um exemplo de amor às próprias capacidades intelectuais. 


\title{
Quaestio Iuris
}

vol. 13, nº.01, Riode Janeiro, 2020. pp. 303-321

DOI: $10.12957 /$ rqi.2020.44834

Vejamos então apenas mais uma passagem de "Da amizade":

Mas tinha [La Boétie] soberanamente gravada na alma uma outra máxima, a de obedecer e submeter-se muito escrupulosamente às leis sob as quais nascera. Nunca houve um cidadão melhor, nem mais afeiçoado à tranquilidade de seu país, nem mais inimigo das agitações e novidades de seu tempo. De muito melhor grado ele empregaria seu talento em extingui-las do que em fornecer-lhes com que incitá-las ainda mais. Tinha o espírito moldado pelo padrão de outros séculos que não este. (Ensaios, I, XXVIII, p. 290, negrito).

Conforme sugiro na passagem, como acréscimo, o texto é uma reflexão sobre a amizade a Etienne de La Boétie ${ }^{7}$ e ao mundo social. As regras são injustas, Montaigne assim sugere-nos, mas são

\footnotetext{
${ }^{7}$ o que "está na nossa natureza o deixarmos que os deveres da amizade ocupem boa parte da nossa vida" (La Boétie, 2009, p. 10)
}

\section{SKEPTICISM IN JUSTICE AND LAW IN MONTAIGNE}

\begin{abstract}
The article presents what may be the role of skepticism for the law in Michel de Montaigne's thought (1533-1592). First of all, it discusses justice through a solipsistic attitude. It then identifies how the right can be configured from the essayist's pyrrhic skepticism. It is argued that skepticism appears as a diagnosis and as an instrument of intervention by justice. At the end of the paper, pointing to montaignian law as an instrument of continuous imperfection, disjointed from any dogmatic basis.
\end{abstract}

Keywords: pyrrhonism, skepticism, Montaigne, justice, law

\section{REFERENCIAS}

CONCEIÇÃO, Gilmar Henrique da. Montaigne e a lei: sobre o Do costume de não mudar facilmente uma lei aceita (I, 23) e Da experiência (III, 13). Revista Quastio Iuris, Rio de Janeiro, vol.08, nº. 02, pp. 898-919. 2015. DOI: http://dx.doi.org/10.12957/rqi.2015.16912

EVA, Luiz. Montaigne, leitor de sexto empírico: a crítica da filosofia moral. Kriterion, Belo Horizonte, v. 53, n. 126, p. 397-419, Dec. 2012 . Available from <http://www.scielo.br/scielo.php?script=sci_arttext\&pid=S0100512X2012000200005\&lng=en\&nrm=iso $>$. access $\quad$ on 11 July $2019 . \quad$ http://dx.doi.org/10.1590/S0100$512 \times 2012000200005$.

FRAME, Donald M. What Next in Montaigne Studies? The French Review, Vol. 36, No. 6, pp. 577-587, May. 1963.

FRIEDRICH, Hugo. Montaigne. Translated by Dawn Eng. Berkeley: University of California Press, 1991.

GOMES, D. M.; PALIOLOGO, N. A. Direito e linguagem no pensamento de Montaigne. Revista Brasileira de Filosofia do Direito, Salvador, v. 4, n. 1, p. 1 - 18, Jan/Jun. 2018.

KIRALY, C. Positivismo jurídico e ceticismo: elementos de ficção e acústica, CSOnline - REVISTA ELETRÔNICA DE CIÊNCIAS SOCIAIS, n. 14, 13 maio. 2012. DOI: https://doi.org/10.34019/19812140.2012.v0.17216

SOCIETÉ DES AMIS DE MONTAIGNE. Acessível em: http://www.amisdemontaigne.fr/

LEITÃo, Macel. Revista de Estudos Constitucionais, Hermenêutica e Teoria do Direito (RECHTD), São Leopoldo (RS), 8(1): 74-84, janeiro-abril. 2016. DOI: 10.4013/rechtd.2016.81.08

LA BOÉTIE, Etienne de. Discurso sobre a servidão voluntária. Brasília: LGE Editora, 2009. 
públicas, não são privadas, portanto, têm na conta do assentimento capaz de produzir solução à dissipação. Entre duas sugestões, é imperioso anotar que ele tem lado, o lado da ciência de regras como fenômeno decantado no tempo. As agitações, a guerra civil, por seu lado, tem na letalidade dos envolvidos a disposição contrária às fricções normais ocorridas na amizade, no regramento. A dicotomia enfrentada pelo ensaísta é a amizade de um lado, em que pese a sua imensa disposição para o injusto, versus a animosidade e a letalidade dissipadoras. Submeter-se às leis é submeter-se à amizade, ao sentimento coletivo, à razão coletiva, à razão pública. São duas tiranias: a do tirano

MONTAIGNE, Michel de. Os Ensaios. Tradução de Rosemary Abílio. 2a edição. São Paulo: Martins Fontes, 2002. (Paideia, Livro I). . Tradução de Rosemary Abílio. 2a edição. São Paulo: Martins Fontes, 2006. (Paideia, Livro II).

MONTAigne, Michel de. Os Ensaios. Tradução de Sérgio Milliet. São Paulo: Nova Cultural, 1996. (Coleção Os Pensadores, 3 Volumes).

MONTAIGNE, Michel de. The Complete Essays of Montaigne. Translated by Donald M. Frame. Stanford: Stanford University Press, 1965. Originalmente publicado em 1957 como The Complete Works of Montaigne.

MOnTAigne, Michel de. The Essays/ The Works of Michel de Montaigne. Tradução (francês/inglês) Charles Cotton. [S.1.]: Liberty Fund - Website. Disponível em: <http://oll.libertyfund.org/>. Acesso em 2010.

MONTAIGNE, Michel de. Les Essais. Versão Digital. eBooks France, [S.1.], Maio, 2000. Disponível em: $<$ www.ebooksfrance.com>. 3 Volumes. Acesso em 2010.

MONTAIGNE, Michel de. The Journal of Montaigne's Travels in Italy by way of Switzer-land and Germany in 1580 and 1581. Translated and Edited with an introduction and notes by W. G. Waters. In three volumes. Vol. I. London: John Murray, Albemarle Street, 1903. Reimpresso por University of Toronto Libraries, Janeiro de 2013.

MBEMBE, Achille. Necropolítica. Arte \& Ensaios: revista do ppgav/eba/ufrj, n. 32, dezembro. 2016.

POPKIN, Richard H. História do ceticismo: de Erasmo a Spinoza. Tradução Danilo Marcondes de Souza Filho. Rio de Janeiro: Francisco Alves, 2000.

RAWLS, John. Uma teoria da justiça. São Paulo: Martins Fontes, 2000.

po

SMITH, Plínio Junqueira. O método cético da oposição e as fantasias de Montaigne. Kriterion, Belo Horizonte, v. 53, n. 126, p. 375-395, Dec. 2012. Available from $<$ http://www.scielo.br/scielo.php?script=sci_arttext\&pid=S0100$512 X 2012000200004 \& \operatorname{lng}=$ en\&nrm=iso $>$. access on 11 July 2019 . http://dx.doi.org/10.1590/S0100$512 \times 2012000200004$.

SEXTUS EMPIRICUS. Outlines of Scepticism. New York: Cambridge University Press, 2000. Ed. ANNAS, Julia and BARNES, J.

SKINNER, Quentin. As fundações do pensamento político moderno. Tradução Renato Janine Ribeiro. São Paulo: Companhia das Letras, 1996.

THEOBALDO, Maria Cristina. História e exercício do julgamento em Montaigne. Kriterion, Belo Horizonte, v. 53, n. 126, p. 527-541, Dez. 2012. Disponível em: $<$ http://www.scielo.br/scielo.php?script=sci_arttext\&pid=S0100$512 X 2012000200013 \& \operatorname{lng}=$ en\&nrm=iso $>$. Acessado em 08 Agosto de 2019. http://dx.doi.org/10.1590/S0100$512 X 2012000200013$. 
acossado por La Boétie e a da guerra civil acossada por Montaigne. O que as une é a falta da ciência de regras.

\section{CONSIDERAÇÕES FINAIS}

O papel do ceticismo para o direito é o de uma solução, não exclusiva, de regressão da vitalidade do erro na vida intelectual e na atividade científica em particular. Os juízos dos homens erram, o artifício do direito vacila enquanto a experiência nos acalma, assim sugerimos o estilo montaigniano de dizer o mundo social justo. Das múltiplas definições do que pode ser a obra de Michel de Montaigne e de como interpretá-la, adotamos uma versão de ceticismo que aglutina a falha e a certeza sobre o mundo com a mesma força. Os céticos duvidam, os céticos pirrônicos como o ensaísta duvidam inclusive das próprias dúvidas sobre as certezas. Portanto, além de estilo e de decisão pragmática, empregamos o pirronismo como meio para apontar e dizer os Ensaios, ainda que pese sobre o ceticismo e o direito uma agenda tão escassa quanto relevante de trabalhos. Para um mundo de instituições públicas em franco desacordo, Os Ensaios respondem com um tipo de linguagem diafônica de coerência assustadora, de modo que a convergência entre a linguagem errática e os fenômenos de dissipação do ordenamento possuem implicações múltiplas.

Além dessa primeira conclusão, a de que a diafonia pirrônica é uma guia razoavelmente segura para interpretar Montaigne e Os Ensaios, destacamos o solipsismo e uma ciência de regras não dogmáticas, tão ao gosto de nossas ambições contemporâneas. Em primeiro lugar, diante de um mundo em colapso, seja pela derrocada do período medieval, pela descoberta do Novo Mundo, pela emergência do que chamamos de moderno, pela certeza dilacerante de reformadores e de contra reformadores, o recolhimento solipsista aparece com força de norma pedagógica para a vida e para a civilização nos Ensaios. A justiça nos aparece no momento do recolhimento, da moderação intramuros, na solidão das nossas imperfeições privadas em cotejo aberto ao mundo social. Esse exercício de introspecção medida e cálida aponta para a moderação das afecções dogmáticas, para a castração do nosso ímpeto tão imperfeito quanto açodado. O justo aparece-nos pela bula solipsista cética.

O terceiro e último ponto é o papel das regras e da ciência de regras na sociedade como resultado da experiência coletiva. O direito que sugerimos de Montaigne é uma obra de imperfeição e de experimento coletivo valorado pela soma de crenças que o tempo lhe oferece e menos pela parcela 
do conhecimento oferecido pelas investidas da razão. No direito de Montaigne não há um fundo racional, uma base sólida a partir da qual conduzimos os nossos conflitos e procuramos ordenar nossos antagonismos. Pelo contrário, a obra imperfeita do homem recai sobre o direito, de modo que a autoridade da regra se origina do depósito repetido de crenças e de repetições de experiências sociais. O que funda o direito é um saber exotérico. Por outro lado, um dogmático pensa ser possível ligar o passado, o presente e o futuro numa coligação idiótica de concatenação do tempo e idiossincrasias. A afecção dogmática pensa a razão como veículo incontornável para o aperfeiçoamento desses tempos baseados na capacidade humana de colocar sobre o mundo um eterno aprimoramento. Em Montaigne, isso é um aborrecimento intransigente com uma vida de transigências, de abalos, de colapsos e de incertezas.

Trabalho enviado em 27 de agosto de 2019

Aceito em 19 de maio de 2020 